\title{
Mechanical and Energy Properties of Pellets Formed from Walnut Shells Blended with Spruce Sawdust
}

\author{
Nikola Čajová Kantová, a,* Alexander Čaja, ${ }^{\mathrm{b}}$ Pavol Belány, ${ }^{\mathrm{a}}$ Zuzana Kolková, ${ }^{\mathrm{a}}$ \\ Peter Hrabovský, ${ }^{\mathrm{a}}$ Dávid Hečko, ${ }^{\mathrm{a}}$ and Pavol Mičko ${ }^{\mathrm{a}}$
}

\begin{abstract}
Various waste materials have energy potential. It is important to make use of this potential and prepare the product for further use by treating the waste. Treatments such as compressing waste into pellets leads to increasing the energy density of this fuel, which benefits transport and storage costs. However, low bulk density, high ash content, low-ash melting temperatures, and low calorific values of non-woody pellets can cause problems during their combustion. This article deals with the energy usage of walnut shells, which were blended with spruce sawdust in various amounts and compressed into pellets. The mechanical and energy properties of these were measured and compared with recommended or standardized values. The formed pellets met the quality limit for bulk density, ash content, moisture content, the content of nitrogen and sulfur, and net calorific value according to ISO 17225. However, low ash melting temperatures were noticed for pellets from pure walnut shells, and also lower mechanical durability for produced pellets with walnut shells contents higher than $10 \%$ were detected.
\end{abstract}

DOI: 10.15376/biores.17.1.1881-1891

Keywords: Waste utilization; Agricultural residual; Biomass; Biofuels; Pellet analysis

Contact information: a: Research centre, University of Zilina, Univerzitna 1, Zilina 01026 Slovakia; $b$ : Department of Power Engineering, Faculty of Mechanical Engineering, University of Zilina,

Univerzitna 1, Zilina 01026 Slovakia; *Corresponding author: nikola.cajovakantova@uniza.sk

\section{INTRODUCTION}

Residual biomass is an important resource to produce energy and is vital in reducing emissions that are typical for fossil fuels. It can be considered carbon-neutral, which is in a line with the interest of the European Union. In general, biomass and also residual biomass has a high moisture content, low mass, and low energy density, which lead to decreasing in heat output (Picchio et al. 2020). This makes it difficult to handle, transport, and store the biomass in its unprocessed form. The solution to these problems can be pelletization because this process leads to the increasing of energy density, besides reducing transport and storage costs. Pellets formed from residual biomass are more homogeneous than unprocessed materials (García et al. 2019).

Wood represents the main component in most formed pellets. It is used as an input material mainly in the form of wood sawdust (Jandačka et al. 2013). In addition to wood, various agricultural residues are also used as the main input materials. However, the quality of such pellets generally is lower than that of wood pellets. The main problems are their low bulk density, high ash content, low ash melting temperatures, and low calorific values (Picchio et al. 2020). Increasing bulk density increases the energy density and decreases transport and storage costs. High ash content causes fouling of furnace equipment and it is 
important to often empty of ash box. High ash content and low ash melting temperatures also lead to the creation of deposit formation, slagging, and sintering (Matúš et al. 2018). When combusting this type of fuel, the kind of burner used as well as the combustion conditions are important to take into account (Werle and Dudziak 2014). The work of Pafčuga et al. (2021) states that a rotary burner allows the combustion of different types of biomass. The rotary burner was also used during the combustion of pellets formed from lawn clippings, corn husks, linden leaves, and pine needles in the work of Trnka et al. (2021). According to Matúš et al. (2018), it is also important to reduce the temperature in the burner place.

Without further use of agricultural residues, the materials often are left to rot in landfills. In the work of García et al. (2019), pellets for industrial usage were produced from pine sawdust and from 11 different biomass residues. It was found that the nitrogen and ash content can be the most important parameters in selecting the ratio of biomass residues and pine sawdust to meet the industrial quality. To ensure industrial quality, one could use only a maximum of $30 \%$ for almond shells, coffee dregs, olive stones, and pinecone leafs, a maximum of $15 \%$ for hazelnut shells, miscanthus, pine kernel shells, and switchgrass, and a maximum of $10 \%$ for coffee husks and grape pomace. The results confirmed that it is possible to create pellets that meet industrial quality by using alternative biomass residues. Rezaei et al. (2020) produced even pellets from paper, plastic, household organic, and wood. Individual components were ground, wetted to $20 \%$ moisture content, and subsequently pelletized. The higher content of plastics from $20 \%$ up to $40 \%$ led to a reduction in energy consumption for pellet production and increased their calorific values. The higher content of paper from $30 \%$ up to $50 \%$ increased the durability of the pellets, but more energy was expended to produce them. Grabowski and Smoliński (2021) tested pellets produced from wood mixed with various types of waste, such as plastic, rubber, paper, diapers, construction, and so on. However, it is necessary to control the usage of waste or other lower-quality fuels in the combustion process.

Nuts crops cover close to $1,200,000$ ha in Europe, and nut waste is up to $40 \%$ of the harvested matter (Noszczyk et al. 2021). The energy and kinetic parameters of various nut shells (walnut, hazelnut, peanut, and pistachio) were investigated in the cited work. The results showed that raw nut shells had relatively high calorific values (17.8 to $19.7 \mathrm{MJ} / \mathrm{kg}$ ) and moisture content in the range of $4.32 \%$ to $9.56 \%$. The elemental characteristics of individual nut shells were found to be similar, but the highest nitrogen content was found in peanut shells. In the work of Acampora et al. (2021), pruning residues from hazelnut and olive groves were used for pellet production. The results showed good quality pellets were produced in terms of profit and energy potential. The ash content, bulk density, and nitrogen content in the case of olive pellets did not meet the legislative requirements. To meet the legislative requirements, the authors proposed to mix the used residues with wood residuals. One of the goals of the work of Perea-Moreno et al. (2018) was to investigate peanut residues in terms of energy potential and thus evaluate the energy parameters of peanut shells as biofuels. The authors found that peanut shells have higher calorific values compared to olive stones or almond shells. However, the ash content of peanut shells is higher than olive stones or almond shells. Almond shells have been the subject of research in terms of anatomical and chemical properties in the work of Li et al. (2018). The content of lignin was also determined in various types of nutshells. Walnut shells had the highest content of lignin $(43.70 \% \pm 0.57 \%)$.

It is important to use the energy potential of various waste materials in line with the decreasing of emissions compared to fossil fuels. This article deals with the usability and 
testing of walnut shells in pellets in various amounts given by their weight proportions. They were blended with spruce sawdust for the production of pellets. Pellets were created using a small pellet press. Then they were tested for their mechanical and energy parameters, such as bulk density, particle density, mechanical durability, elemental analysis, proximate analysis, calorific values, and ash melting temperatures. Their properties were compared with recommended or standardized values for their further application.

\section{EXPERIMENTAL}

In this work spruce sawdust and walnut shells were used as input materials as stated in Fig. 1. Walnut shells were shredded using an industrial blender. The original moisture content of spruce sawdust was in the range of $45 \%$ to $55 \%$ (wet basis). It was necessary to dry them in the laboratory to bring it up to $12 \%$ to $16 \%$ (dry basis). The original moisture of walnut shells was $8 \%$ to $9 \%$ (wet basis), and this material was not dried further.
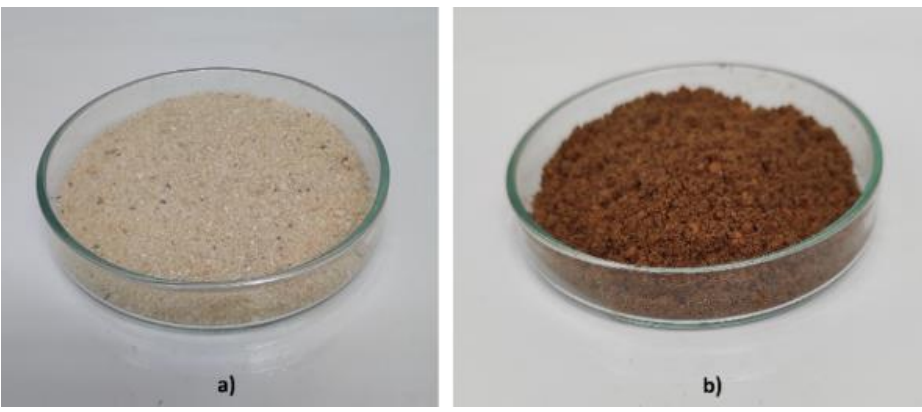

Fig. 1. Input materials: a) Spruce sawdust; and b) Walnut shells

The particle size distribution of the input materials was obtained using vibrating sieve equipment Retsch AS200 (Retsch GmbH, Haan, Germany). Figure 2 shows the difference and weight proportion of spruce sawdust and walnut shells. Both samples had a started weight about of $100 \mathrm{~g}$.

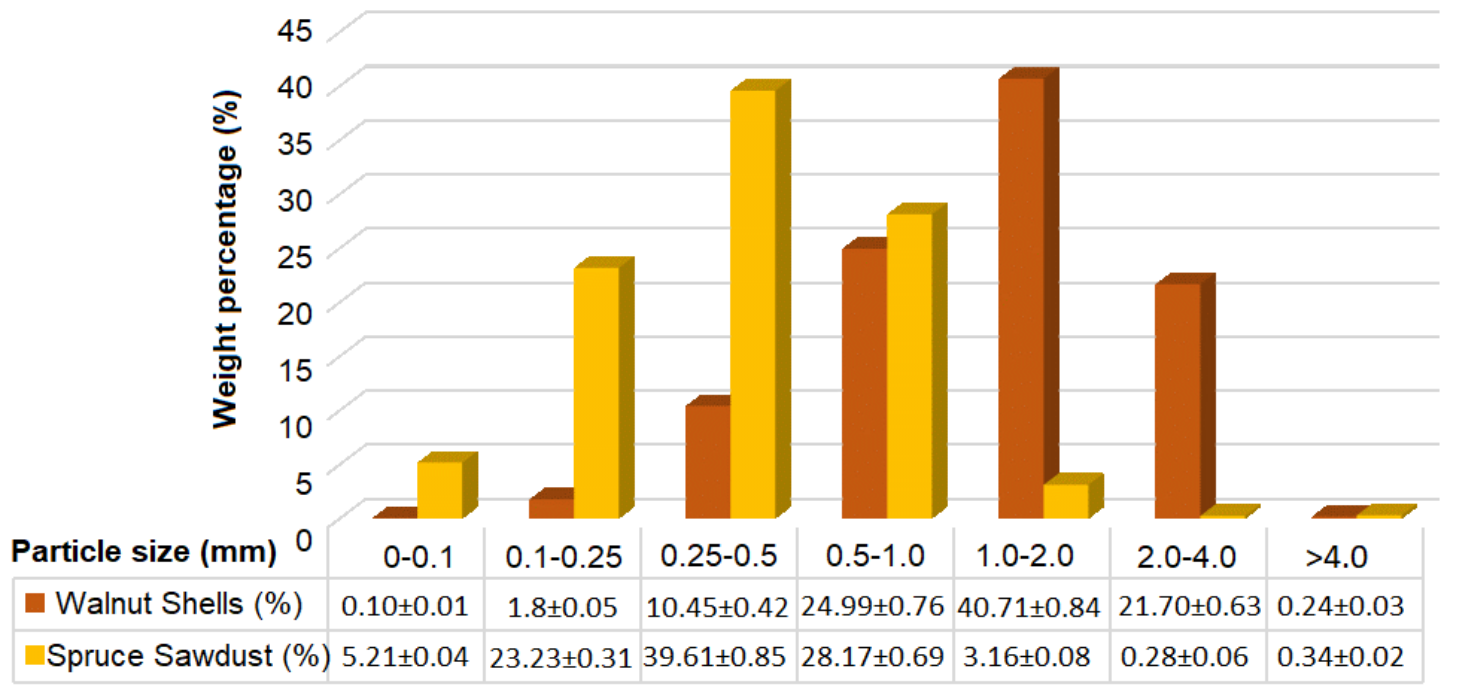

Fig. 2. Particle size distribution 
The difference in particle size was probably due to the crushing process. The used crusher could not crush harder materials, such are walnut shells, into such small particles. The sieve analysis showed a difference in particle size in the materials used, where the spruce sawdust had a higher amount of particles up to $1 \mathrm{~mm}$ and the sample of walnut shells showed the highest concentration of particles above $1 \mathrm{~mm}$.

Input materials were compressed together into pellets using the small pellet press LPBB200V2. In this work, pellets were produced from walnut shells containing spruce sawdust in the different proportions (see the Table 1). The individual pellet samples are stated in Fig. 3.

Table 1. Compositions of Pellet Samples

\begin{tabular}{|c|c|c|}
\hline Sample & Weight Proportion of Walnut Shells (\%) & Weight Proportion of Spruce Sawdust (\%) \\
\hline $0 / 100$ & 0 & 100 \\
\hline $10 / 90$ & 10 & 90 \\
\hline $20 / 80$ & 20 & 80 \\
\hline $30 / 70$ & 30 & 70 \\
\hline $40 / 60$ & 40 & 60 \\
\hline $50 / 50$ & 50 & 50 \\
\hline $60 / 40$ & 60 & 40 \\
\hline $70 / 30$ & 70 & 30 \\
\hline $80 / 20$ & 80 & 20 \\
\hline $90 / 10$ & 90 & 10 \\
\hline $100 / 0$ & 100 & 0 \\
\hline
\end{tabular}
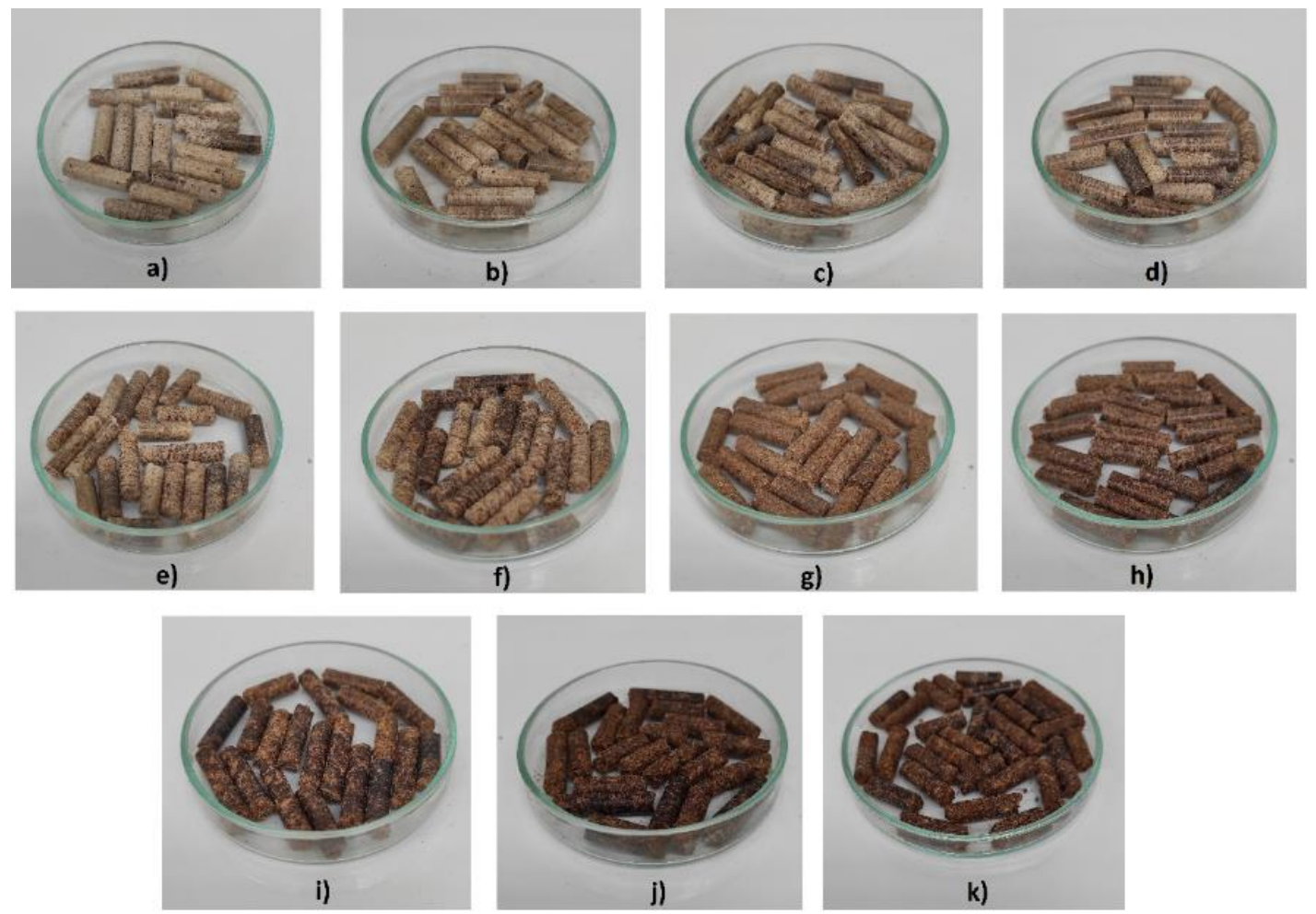

Fig. 3. Pellet samples: a) $0 / 100$; b) $10 / 90$; c) $20 / 80$; d) $30 / 70$; e) $40 / 60$; f) $50 / 50$; g) $60 / 40$; h) $70 / 30$; i) $80 / 20$; j) $90 / 10$; k) 100/0 
The pellet press operated with an output of $7.5 \mathrm{~kW}$ and at a lower pressure than that achieved with larger industrial pelletizers. The created pellets were produced under the same conditions and had a diameter of about $6 \mathrm{~mm}$. All pellet samples were stored in a laboratory at the temperature of $20{ }^{\circ} \mathrm{C}$ and relative humidity from $40 \%$ to $50 \%$. After one week of storage, the properties of created pellets were tested.

The formed pellets were tested for their mechanical and energy parameters, such as bulk density, particle density, mechanical durability, elemental analysis, proximate analysis, calorific values, and ash melting temperatures.

The bulk density was calculated from the net weight per defined volume according to ISO 17828 (2015). The particle density was determined as the ratio between weight and volume of pellets. In this case, pellet weight was measured by digital weight, and volume was calculated as a cylinder volume with its length and diameter according to ISO 17829 (2015). To achieve parallel faces of the pellets, the individual areas were sanded.

The mechanical durability was measured using a Ligno-Tester Holmen device (Tekpro Ltd., North Walsham, UK). The pellet samples of $100 \mathrm{~g}$ were put in a Ligno-Tester and rotated there for $60 \mathrm{~s}$, while they were subjected to controlled impacts. Differences between pellet weight before and after the test allow the calculation of mechanical durability.

The elemental analysis was realized on an elemental analyzer CHN628 (Leco Corporation, St. Joseph, MI, USA) with a separate module for the determination of sulfur content. Individual samples were weighed with an approximate value of $0.1 \mathrm{~g}$ for the detection of $\mathrm{C}, \mathrm{H}$, and $\mathrm{N}$ and of $0.25 \mathrm{~g}$ for sulfur detection. Pre-weighed samples were combusted in the absence of atmospheric gases. After this combustion in the combustion chamber, the contents of $\mathrm{C}, \mathrm{H}$, and $\mathrm{N}$ gases can be detected. The presence of sulfur content was detected in the separate module at a higher temperature of about $1350{ }^{\circ} \mathrm{C}$.

The proximate analysis was realized using a thermogravimetric analyzer TGA 701 (Leco Corporation, St. Joseph, MI, USA). This analyzer measures the weight loss of samples in a defined atmosphere, while their temperatures are gradually increasing. Using this device, it can be possible to determine the content of moisture, volatile matter, fixed carbon, and ash. Individual samples were weighted with an approximate value of $1.2 \mathrm{~g}$ and heated at $107{ }^{\circ} \mathrm{C}$ for the determination of moisture content in the air atmosphere. Then the temperature was increased at $900{ }^{\circ} \mathrm{C}$ for the determination of the volatile matter in the nitrogen atmosphere. Finally, the temperature was decreased at $550{ }^{\circ} \mathrm{C}$ in air atmosphere, where ash content was detected.

The measurement of higher calorific values was realized on a calorimeter Leco AC 500 (Leco Corporation, St. Joseph, MI, USA). Individual samples were weighed with an approximate value of $1 \mathrm{~g}$. Lower calorific values were calculated using measured higher calorific values using Eq. 1.

$$
\begin{aligned}
& \mathrm{LCV}=\mathrm{HCV}-r_{H 2 O}\left(W_{p}+8.94 x_{H}\right) \\
& x_{H}=0.01 \cdot H_{h} \cdot B_{p}
\end{aligned}
$$

Equation 1 contains $r_{\mathrm{H} 2 \mathrm{O}}$, which denotes water heat of vaporization $(\mathrm{kJ} / \mathrm{kg}) ; W_{\mathrm{p}}$ represents the water content (wt.\%); hydrogen to water conversion coefficient with the value of 8.94; and $x_{\mathrm{H}}$ is obtained from Eq. 2. In Eq. 2, $H_{\mathrm{h}}$ is the hydrogen content (wt.\%), and $B_{\mathrm{p}}$ is volatile content (wt.\%) of tested samples (Nosek et al. 2021).

The determination of ash melting temperatures was realized using a temperature analyzer Leco AF 700 (Leco Corporation, St. Joseph, MI, USA). This analyzer measures 
four standardized ash-melting temperatures: (1) The shrinkage temperature (ST); (2) the deformation temperature (DT); (3) the hemisphere temperature (HT); and (4) the flow temperature (FT). Investigated temperatures were determined according to ISO 540 (2008).

All measurements were repeated three to five times, with the resulting values being their mean values with the calculated sample standard deviation. Determination of sample standard deviation (STDEV) was performed for all measurements according to Eq. 3 .

$$
S T D E V=\sqrt{\frac{1}{(n-1)} \sum_{i=1}^{n}\left(x_{i}-\bar{x}\right)^{2}}
$$

In Eq. 3, $n$ is the sample size, $x_{i}$ is the individual sample values, and $\bar{x}$ is the sample mean.

\section{RESULTS AND DISCUSSION}

Results from the measurement of bulk density are shown in Fig. 4. All tested pellets had bulk density higher than $600 \mathrm{~kg} / \mathrm{m}^{3}$, but lower than $700 \mathrm{~kg} / \mathrm{m}^{3}$. Wood pellets used for commercial and residential applications including non-woody pellets (made from herbaceous, fruit, and aquatic biomass, and also mixtures with wood) should have a bulk density higher than $600 \mathrm{~kg} / \mathrm{m}^{3}$ according to ISO 17225 (2014). This limit was achieved for all tested pellets prepared from spruce sawdust and walnut shells.

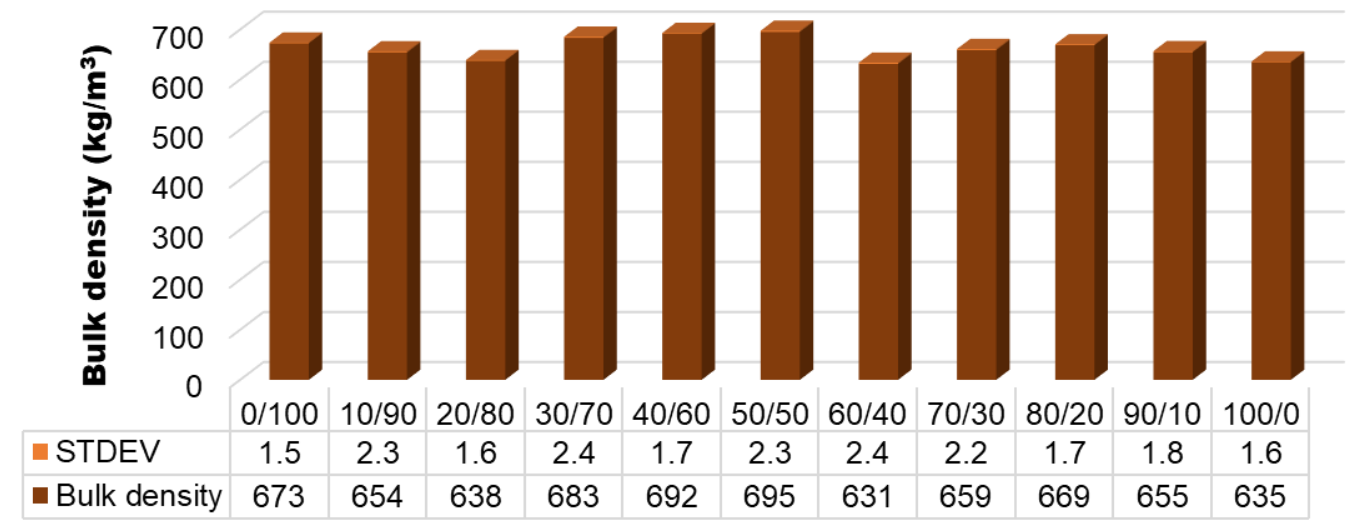

Fig. 4. Bulk density of tested pellets: $(0 / 100)$ The weight proportion of walnut shells is $0 \%$ and the weight proportion of spruce sawdust is $100 \%$; $(10 / 90)$ The weight proportion of walnut shells is $10 \%$ and the weight proportion of spruce sawdust is $90 \%$; and so on

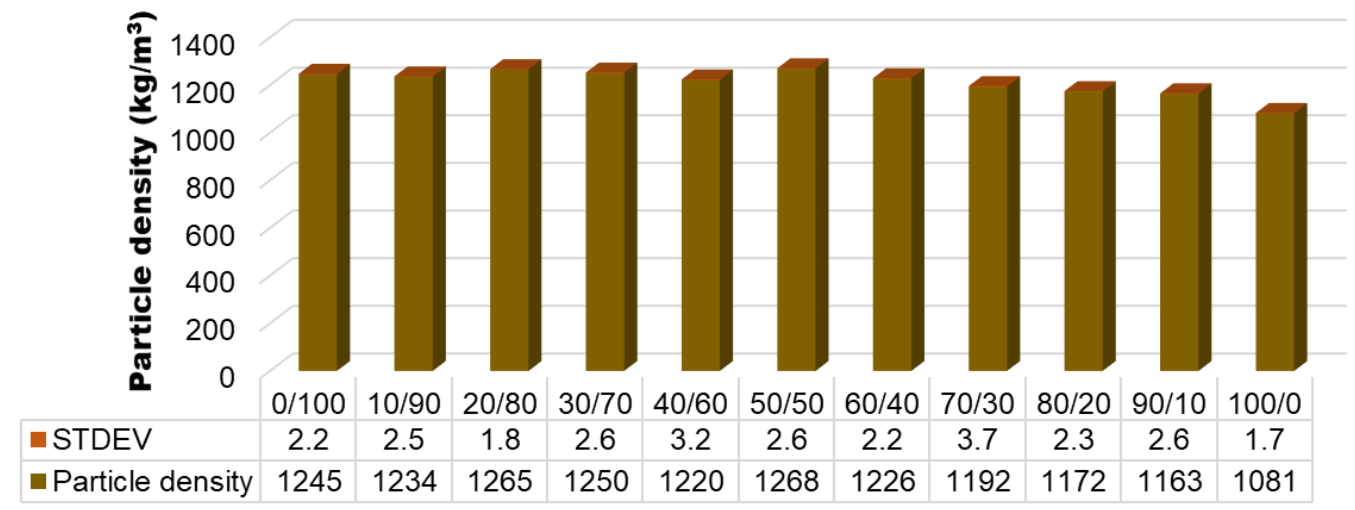

Fig. 5. Particle density of tested pellets 
Figure 5 shows results from the measurement of particle densities of formed pellets. All tested pellets had particle density in the range from $1081 \mathrm{~kg} / \mathrm{m}^{3}$ to $1268 \mathrm{~kg} / \mathrm{m}^{3}$. Wood pellets have a recommended value of particle density in the range from $1000 \mathrm{~kg} / \mathrm{m}^{3}$ to 1400 $\mathrm{kg} / \mathrm{m}^{3}$ according to Stelte et al. (2011). These recommended values are attained for all tested pellets.

Results of the measurement of mechanical durability (DU) are indicated in Fig. 6. Wood and non-woody pellets should have mechanical durability higher than $97.5 \%$ to meet the limit of quality A and higher than $96.5 \%$ (wood) or $96.0 \%$ (non-woody) to meet the limit of quality B according to ISO 17225 (2014). Pure pellets from spruce sawdust met the limit value for quality A. Pellets with $10 \%$ of walnut shells met the limit value for quality B. Other formed pellets did not pass the test of mechanical durability. The mechanical durability can be also increased using additives, such as concentrate of organic compounds (Jandačka et al. 2013).

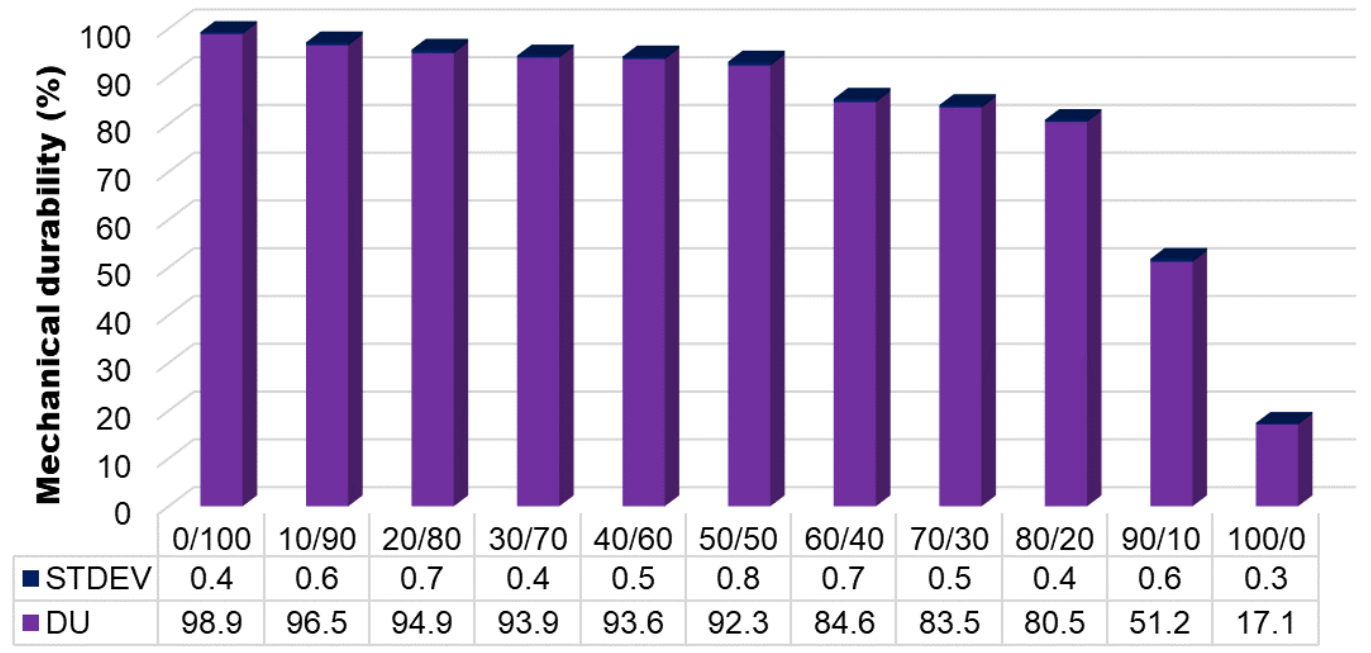

Fig. 6. Mechanical durability of tested pellets

Table 2. Elemental Analysis of Tested Pellets

\begin{tabular}{|c|c|c|c|}
\hline Sample & C-content (\%) & H-content (\%) & N-content (\%) \\
\hline $0 / 100$ & $46.78 \pm 0.25$ & $6.37 \pm 0.03$ & 0.00 \\
\hline $10 / 90$ & $46.31 \pm 0.03$ & $6.27 \pm 0.04$ & 0.00 \\
\hline $20 / 80$ & $47.47 \pm 0.07$ & $6.37 \pm 0.05$ & 0.00 \\
\hline $30 / 70$ & $46.06 \pm 0.13$ & $6.37 \pm 0.05$ & 0.00 \\
\hline $40 / 60$ & $47.32 \pm 0.02$ & $6.35 \pm 0.04$ & 0.00 \\
\hline $50 / 50$ & $47.27 \pm 0.14$ & $6.37 \pm 0.03$ & 0.00 \\
\hline $60 / 40$ & $46.80 \pm 0.10$ & $6.45 \pm 0.03$ & 0.00 \\
\hline $70 / 30$ & $47.01 \pm 0.24$ & $6.47 \pm 0.06$ & 0.00 \\
\hline $80 / 20$ & $47.03 \pm 0.12$ & $6.45 \pm 0.06$ & $0.01 \pm 0.01$ \\
\hline $90 / 10$ & $47.14 \pm 0.10$ & $6.52 \pm 0.07$ & $0.11 \pm 0.05$ \\
\hline $100 / 0$ & $47.92 \pm 0.14$ & $6.51 \pm 0.02$ & $0.13 \pm 0.05$ \\
\hline
\end{tabular}

Table 2 shows the results of elemental analysis such as the contents of $\mathrm{C}, \mathrm{H}$, and $\mathrm{N}$. The content of sulfur was not detected. Wood pellets should have a N-content lower than 
$0.3 \%$ and a S-content lower than $0.04 \%$ to meet the limit of quality A1 according to ISO 17225 (2014). Non-woody pellets should have a N-content lower than $1.5 \%$ and a Scontent lower than $0.2 \%$ to meet the limit of quality A according to ISO 17225 (2014).

All tested pellets met the limit values for contents of nitrogen and sulfur for quality A. It can be seen that the contents of carbon and hydrogen increased slightly with increasing the content of walnut shells.

Table 3 shows the results of proximate analysis, such as the contents of moisture, volatile matter, fixed carbon, and ash. Wood pellets should have a moisture content lower than $10 \%$ (for non-woody pellets lower than $12 \%$ ) to meet the limit of quality A according to ISO 17225 (2014). All tested pellets had a moisture content lower than $10 \%$. As ash content for wood pellets should be lower than $0.7 \%$ to meet the limit of quality A1 according to ISO 17225 (2014), pure pellets met this limit. However, all non-woody pellets also met the limit in their category. The ash content for non-woody pellets should be lower than $6 \%$ to meet the limit of quality $\mathrm{A}$ and lower than $10 \%$ to meet the limit of quality B.

Table 3. Proximate Analysis of Tested Pellets

\begin{tabular}{|c|c|c|c|c|}
\hline Sample & Moisture (\%) & Volatile Matter (\%) & Fixed Carbon (\%) & Ash (\%) \\
\hline $0 / 100$ & $8.90 \pm 0.07$ & $74.69 \pm 0.12$ & $16.00 \pm 0.15$ & $0.41 \pm 0.01$ \\
\hline $10 / 90$ & $8.58 \pm 0.38$ & $70.84 \pm 0.76$ & $19.98 \pm 0.63$ & $0.59 \pm 0.18$ \\
\hline $20 / 80$ & $8.05 \pm 0.13$ & $74.06 \pm 0.22$ & $17.09 \pm 0.02$ & $0.80 \pm 0.08$ \\
\hline $30 / 70$ & $7.23 \pm 0.09$ & $74.77 \pm 0.79$ & $17.15 \pm 0.69$ & $0.86 \pm 0.01$ \\
\hline $40 / 60$ & $7.45 \pm 0.18$ & $73.80 \pm 0.06$ & $17.60 \pm 0.21$ & $1.14 \pm 0.05$ \\
\hline $50 / 50$ & $7.08 \pm 0.05$ & $73.24 \pm 0.12$ & $18.47 \pm 0.06$ & $1.21 \pm 0.01$ \\
\hline $60 / 40$ & $8.26 \pm 0.62$ & $70.79 \pm 0.68$ & $19.48 \pm 0.79$ & $1.47 \pm 0.04$ \\
\hline $70 / 30$ & $6.71 \pm 0.07$ & $73.12 \pm 0.12$ & $18.43 \pm 0.15$ & $1.74 \pm 0.08$ \\
\hline $80 / 20$ & $6.61 \pm 0.03$ & $73.17 \pm 0.19$ & $18.37 \pm 0.16$ & $1.85 \pm 0.07$ \\
\hline $90 / 10$ & $6.13 \pm 0.02$ & $72.70 \pm 0.04$ & $19.18 \pm 0.12$ & $1.98 \pm 0.08$ \\
\hline $100 / 0$ & $6.03 \pm 0.12$ & $72.51 \pm 0.21$ & $19.29 \pm 0.12$ & $2.17 \pm 0.03$ \\
\hline
\end{tabular}

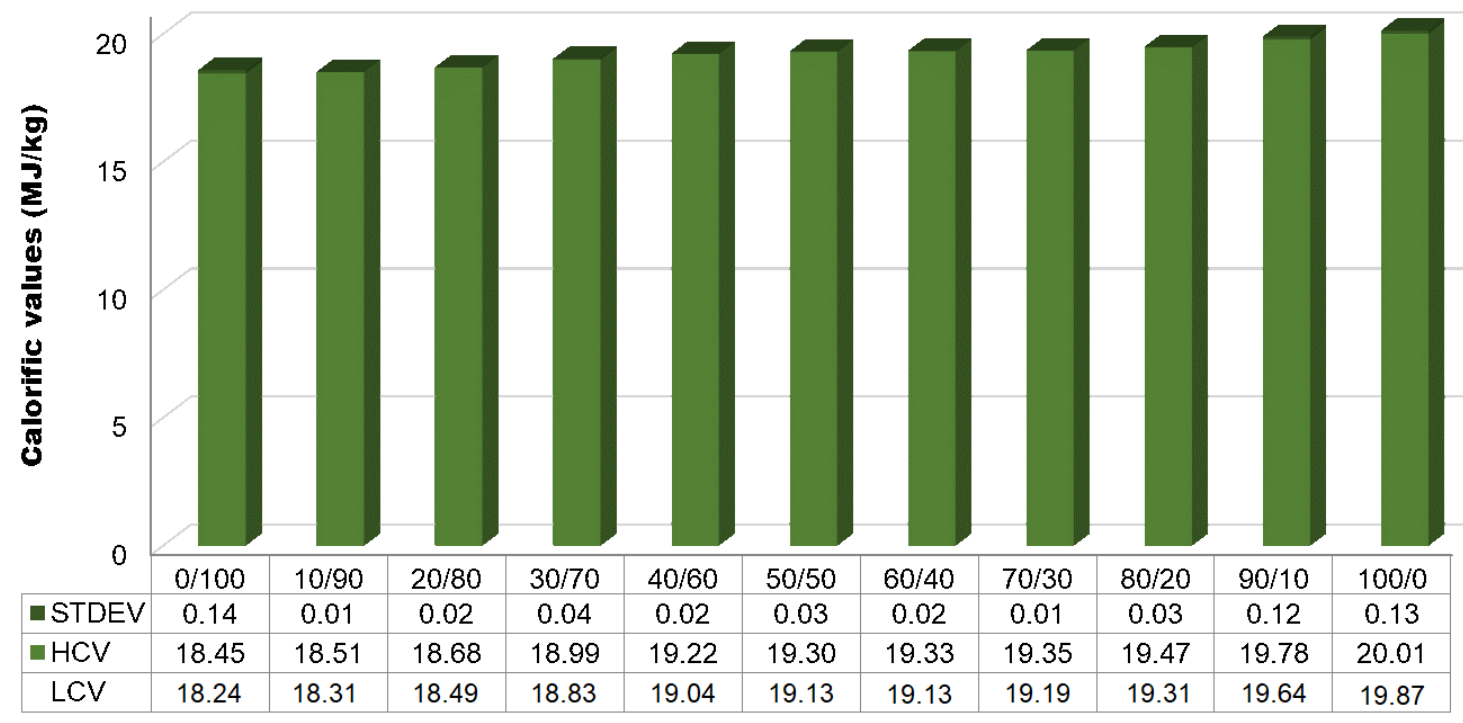

Fig. 7. Calorific values of tested pellets 
The calorific values are quantified in Fig. 7. Wood pellets should have a net calorific value (also known as lower calorific value) higher than $16.5 \mathrm{MJ} / \mathrm{kg}$, and nonwoody pellets should have a net calorific value higher than $14.5 \mathrm{MJ} / \mathrm{kg}$ to meet the limit of quality A and B. This limit was met for all pellets formed from pure spruce sawdust and also from non-woody materials as pure walnut shells or their mixture with spruce sawdust. With the increasing amount of walnut shells, the calorific values also were increased.

Figure 8 presents results from the measurement of ash melting temperatures. The maximum working temperature used in the analyzer was $1500{ }^{\circ} \mathrm{C}$. The spruce wood has the following ash melting temperatures: (1) DT in the range from $1110^{\circ} \mathrm{C}$ to $1340{ }^{\circ} \mathrm{C}$; (2) ST in the range from $1410{ }^{\circ} \mathrm{C}$ to $1640{ }^{\circ} \mathrm{C}$; (3) $\mathrm{HT}$ in the range from $1630{ }^{\circ} \mathrm{C}$ to $1700{ }^{\circ} \mathrm{C}$; and (4) FT higher than $1700{ }^{\circ} \mathrm{C}$ according to Van Loo and Koppejan (2008). In general, non-woody biomass has lower values of ash melting temperatures than wood biomass, which is also confirmed by the measured results. Pure pellets from walnut shells had the lowest ash melting temperatures. Low ash melting temperatures of fuels can cause sintering or slagging during their combustion.

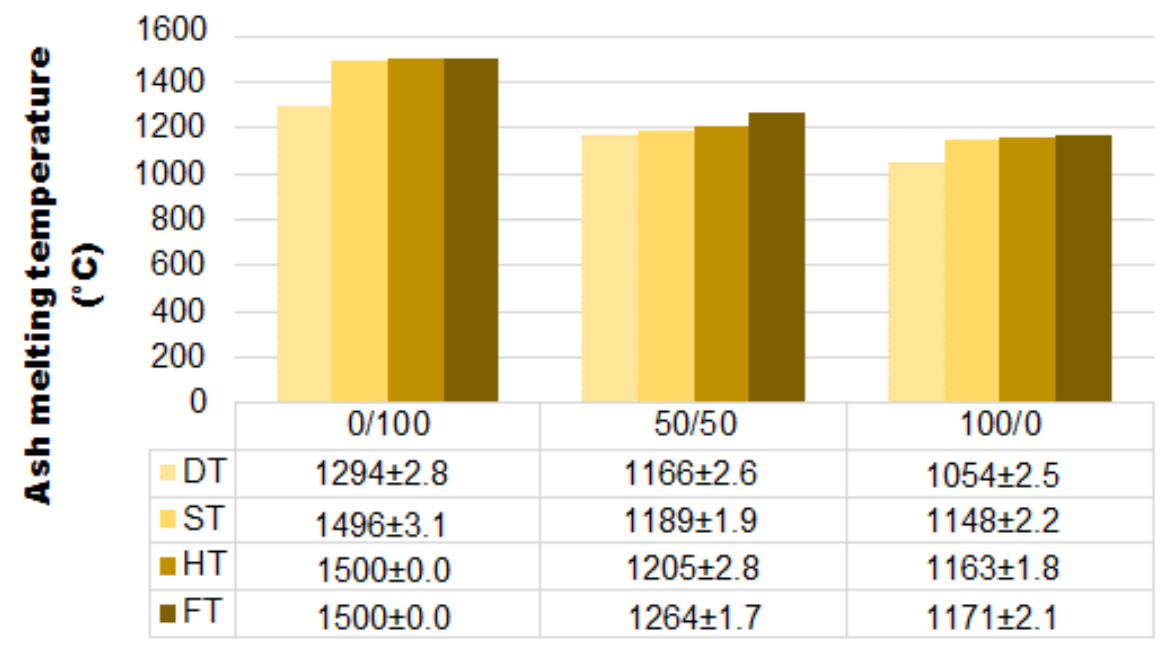

Fig. 8. Ash melting temperatures of tested pellets: (DT) Deformation temperature; (ST) Shrinkage temperature; (HT) Hemisphere temperature; (FT) Flow temperature

\section{CONCLUSIONS}

1. All pellets formed from spruce sawdust and walnut shells met the quality limit for bulk density, ash content, moisture content, the contents of nitrogen and sulfur elements, and net calorific value according to ISO 17225 (2014). However, most of the measured values of mechanical durability were lower than stated in this standard.

2. Measured values of ash melting temperatures were decreasing with the increasing content of walnut shells, which can cause sintering or slagging during combustion. It is recommended to mix non-woody material with wood material, which increases ash melting temperatures compared with pure non-woody material.

3. Based on the results, it can be concluded that walnut shells are useable agricultural residuals in the pelletization process as input material by blending with spruce sawdust for heating purposes. 


\section{ACKNOWLEDGMENTS}

This publication has been produced with the support of the Integrated Infrastructure Operational Program for the project: Creation of a Digital Biobank to support the systemic public research infrastructure, ITMS: 313011AFG4, co-financed by the European Regional Development Fund and Grant System of University of Zilina No. 1/2021 (13832).

\section{REFERENCES CITED}

Acampora, A., Civitarese, V., Sperandio, G., and Rezaei, N. (2021). "Qualitative characterization of the pellet obtained from hazelnut and olive tree pruning," Energies 14, 4083. DOI: 10.3390/en14144083

García, R., Gil, M. V., Rubiera, F., and Pevida, C. (2019). "Pelletization of wood and alternative residual biomass blends for producing industrial quality pellets," Fuel 251, 739-753. DOI: 10.1016/j.fuel.2019.03.141

Grabowski, J., and Smoliński, A. (2021). "The application of hierarchical clustering to analyzing ashes from the combustion of wood pellets mixed with waste materials," Environmental Pollution 276, 116766. DOI: 10.1016/j.envpol.2021.116766

ISO 17225 (2014). "Solid biofuels - Fuel specifications and classes," International Organization for Standardization, Geneva, Switzerland.

ISO 17828 (2015). "Solid biofuels - Determination of bulk density," International Organization for Standardization, Geneva, Switzerland.

ISO 17829 (2015). "Solid biofuels - Determination of length and diameter of pellets," International Organization for Standardization, Geneva, Switzerland.

ISO 540 (2008). "Hard coal and coke. Determination of ash fusibility," International Organization for Standardization, Geneva, Switzerland.

Jandačka, J., Holubčík, M., Malcho, M., and Nosek, R. (2013). "Modification of wood pellets parameters by using of concentrate of organic compounds from defibration," Acta Facultatis Xylologiae Zvolen 55(2), 105-115.

Li, X., Liu, Y., Hao, J., and Wang, W. (2018). "Study of almond shell characteristics," Materials 11, 1782. DOI: 10.3390/ma11091782

Matúš, M., Križan, P., Šooš, L., and Beniak, J. (2018). "The effect of papermaking sludge as an additive to biomass pellets on the final quality of the fuel," Fuel 219, 196-204. DOI: 10.1016/j.fuel.2018.01.089

Nosek, R., Backa, A., Ďurčanský, P., Holubčík, M., and Jandačka, J. (2021). "Effect of paper sludge and dendromass on properties of phytomass pellets," Applied Sciences 11, 65. DOI: 10.3390/app11010065

Noszczyk, T., Dyjakon, A., and Koziel, J. A. (2021). "Kinetic parameters of nut shells pyrolysis," Energies 14, 682. DOI: 10.3390/en14030682

Pafčuga, M., Holubcik, M., Durcansky, P., Kapjor, A., Malcho, M. (2021) "Small heat source used for combustion of wheat-straw pellets, "Applied Sciences 11(11), 5239. DOI: 10.3390/app11115239

Perea-Moreno, M.-A., Manzano-Agugliaro, F., Hernandez-Escobedo, Q., and PereaMoreno, A.-J. (2018). "Peanut shell for energy: Properties and its potential to respect the environment," Sustainability 10, 3254. DOI: 10.3390/su10093254

Picchio, R., Latterini, F., Venanzi, R., Stefanoni, W., Suardi, A., Tocci, D., and Pari, L. (2020). "Pellet production from woody and non-woody feedstocks: a review on 
biomass quality evaluation," Energies 13, 2937. DOI: 10.3390/en13112937

Rezaei, H., Panah, F. Y., Lim, C. J., and Sokhansanj, S. (2020). "Pelletization of refusederived fuel with varying compositions of plastic, paper, organic and wood," Sustainability 12, 4645. DOI: 10.3390/su12114645

Stelte, W., Holm J., Sanadi A., Barsberg S., Ahrenfeldt J., and Henriksen U. (2011). "Fuel pellets from biomass: The importance of the pelletizing pressure and its dependency on the processing conditions," Fuel 90(11), 3285-3290, DOI: 10.1016/j.fuel.2011.05.011

Trnka, J., Holubčík, M., Čajová Kantová, N., and Jandačka, J. (2021). “Energy performance of a rotary burner using pellets prepared from various alternative biomass residues," BioResources 16(4), 6737-6749.

Van Loo, S., and Koppejan, J. (2008). The Handbook of Biomass Combustion and CoFiring, Taylor \& Francis Ltd., London

Werle, S., and Dudziak, M. (2014). "Gaseous fuels production from dried sewage sludge via air gasification," Waste Management and Research 32(7), 601-607. DOI: $10.1177 / 0734242 X 14536460$

Article submitted: October 25, 2021; Peer review completed: January 1, 2022; Revised version received and accepted: January 18, 2022; Published: January 28, 2022.

DOI: $10.15376 /$ biores.17.1.1881-1891 